\title{
Impact of Globalization on Model of Competition and Companies' Competitive Situation
}

\author{
Knut Erik Bang and Tore Markeset \\ University of Stavanger, N-4036 Stavanger, Norway \\ knut.e.bang@uis.no, tore.markeset@uis.no
}

\begin{abstract}
Globalization has changed the competitive environment of companies. This paper aims to contribute to understanding the changes a company can face through analyzing the impact of drivers and effects of globalization on the models of industry competition and the company value chain. The boundaries between the forces of competition are fading as economic globalization has led to a new dynamic in the competitive situation where companies and activities of the value chains change places between forces and impact and interact with each other in new ways. The boundaries of companies and their core can and are being redefined. As this potential evolves through offshoring, outsourcing and value chain fragmentation, the pressure of competition forces a continuing and increasing move in this direction.
\end{abstract}

Keywords: Economic globalization, outsourcing, offshoring, value chain fragmentation, company competition

\section{Introduction}

Economic globalization has changed the world over the last couple of decades. The objective of this study is to contribute to the understanding of how globalization affects the competitive environment of companies. The hypothesis put forward is that the increased competition from globalization has a significant impact on all the five forces of competition [1], creating a new dynamic where the boundaries between the forces and the boundaries of the company fade away. The impact of the drivers and effects of globalization on the forces of competition is evaluated.

In a literature study by Bang and Markeset [2], the main drivers of economic globalization that affect the competitive situation are identified to be 1) lower trade barriers; 2) lower transportation costs; 3) lower communication costs; 4) ICT development; and 5) the spread of technology, as shown in Figure 1.

These have a number of effects that are grouped into the areas of size, location and pressure. The size effects are larger market potential, larger number of potential clients, larger number of potential competitors and larger number of potential suppliers and partners. The location effects are fragmented value chains, offshoring, outsourcing and complex supply chains. The pressure effects are cost and price pressure, higher rate of change, more diverse markets, lower start-up barriers and lower visibility. 


\begin{tabular}{|c|c|c|c|}
\hline Drivers & Effects: Size & Effects: Location & Effects: Pressure \\
\hline Lower trade barriers & Larger market potential & $\begin{array}{l}\text { Fragmented value } \\
\text { chains }\end{array}$ & $\begin{array}{l}\text { Cost and price } \\
\text { pressure }\end{array}$ \\
\hline $\begin{array}{l}\text { Lower transportation } \\
\text { costs }\end{array}$ & $\begin{array}{l}\text { Larger number of } \\
\text { potential clients }\end{array}$ & Offshoring & Higher rate of change \\
\hline $\begin{array}{c}\text { Lower } \\
\text { communication costs }\end{array}$ & $\begin{array}{l}\text { Larger number of } \\
\text { potential competitors }\end{array}$ & Outsourcing & More diverse markets \\
\hline ICT development & $\begin{array}{l}\text { Larger no. of potential } \\
\text { suppliers and partners }\end{array}$ & Complex supply chains & Lower start-up barriers \\
\hline Spread of technology & & & Lower visibility \\
\hline
\end{tabular}

Fig. 1. Summary of the drivers and effects from globalization that affect the competitive situation [2]

When investigating how companies' competitive situations are affected by globalization, it is important to have a clear representation of what we mean by the competitive situation. Michael Porter's model of the five forces on competition [1] has become one of the most established approaches for viewing industry competition, and it is also applicable at the company level. The five forces consist of the industry rivalry between competitors, the bargaining power of buyers, the bargaining power of suppliers, the threat of new entrants and the threat of substitute products or services. To be able to assess the impact of globalization on a company's competitive situation, it will also be necessary to use the representation of a company as a value chain [3]. The company value chain shows the company as a set of value-adding activities linked together.

\section{Effects on the Forces of Porter's Model of Competition}

The drivers and effects of globalization are here evaluated in terms of their impact on the model of the five forces of competition.

\subsection{Drivers}

The drivers of globalization influence the five forces' model, as shown in Figure 2. Lower trade barriers affect the geographic barriers, both in opening up toward similar market segments and their internal competition, but also toward the other potential threats those markets might have. For a multi national company (MNC) that already has a worldwide presence, this can represent more potential competition within the different regions. For smaller and medium-sized companies that are present in a limited number of regions and often have been able to develop under protection from foreign competition, this can have a much more significant effect when their markets are opened up to foreign competition. In terms of the model, the boundaries around the industry competition start to fade away. 


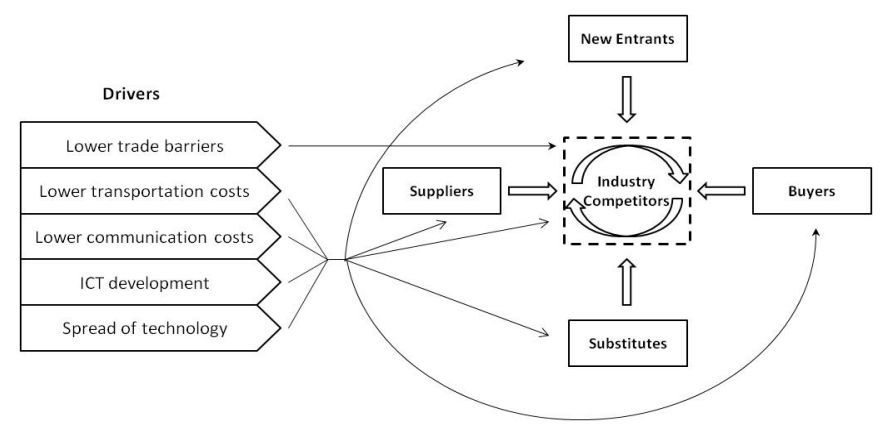

Fig. 2. The drivers of economic globalization and their effects on the forces of competition

Lower transportation costs and lower communication costs affect all the five forces of the model. Lower transportation cost increases sourcing opportunities within the industry, and, for the buyers, and the suppliers, supply options increase. Lower communication costs knit parties of the different forces together and reduce the benefits of previously limited knowledge. The developments within information and communication technology further level the playing field [4] and reduce the benefits of being an established player in the industry. It becomes more difficult to have unique knowledge of market potential, production techniques, methods and industry profitability. It then becomes easier for suppliers to make the step down the value chain or for buyers to decide to take a step up the chain. New entrants will likewise be better informed on the decision of entry. With regard to substitutes, the buyers will be more informed of their potential and they can access market channels more easily. The spread of technology, not only of ICT but also of manufacturing technology, further enables all of the parties to enter the competition. Access to the manufacturing technology may no longer be limited to existing industry players.

The impact of these changes is not only limited to the static picture of the model. The products and services of the competitive situation also change. The developments in ICT have led to digitization of most areas and the inclusion of a new technology in existing areas, or to a replacement of these. Porter [5] demonstrates how the forces of competition are affected by the internet and how the barriers are reduced and differences between competitors and between potential competitors are reduced. He argues that the fundamentals of competition have not changed, though new means of conducting business have become available and the possibilities the internet opens are included in the businesses and the products. In summary, the drivers are tearing down the barriers to industry competition and enable parties of the potential external forces to join in with the competition more easily.

\subsection{Size effects}

The size of a company's competitive arena is arguably the biggest change caused by globalization. As the barriers of the competitive arena are reduced, the potential rivalry of competition includes all the players of previously separate markets now merged into one, as shown in Figure 3. 


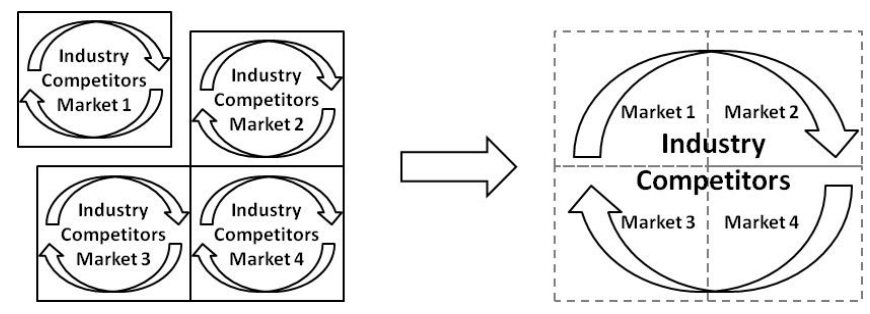

Fig. 3. Merging of separate markets into one large market

This theoretical model does not reflect the diversity and differences in preferences between the segments. However, it does show something more important: the increased number of potential direct competitors. For an individual company, the competitiveness in the integrated market depends on the competitiveness of the industry segment in which it is competing. Highly competitive segments that have been formed in a strong competitive cluster [6] should then in theory be successful also in the integrated market. However, the comparative differences [7] of locations, like wage differences, can change the relative competitiveness. In becoming part of a larger market, the market potential becomes larger, and the number of potential customers increases. While increased market and revenue potential is positive, the increase in number of clients at many locations increases the business complexity and places new requirements on the operation and management of a company. Moreover, all the forces affecting the competitive market increase as well, as shown in Figure 4. There are more potential suppliers to choose from, and more options in terms of how to set up your own value chain. Potential threats from new entries and from substitutes increase in the same fashion.

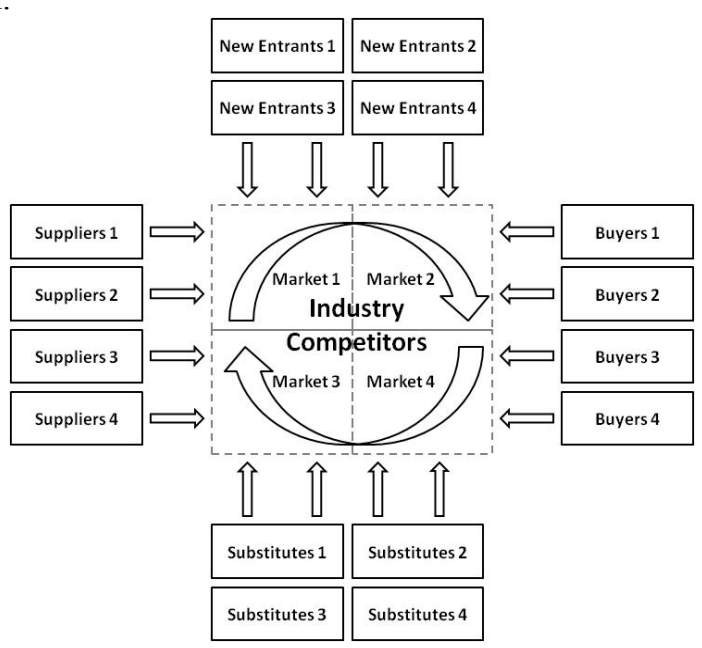

Fig. 4. Expanding the competition model

The model of the five forces of competition changes in the form of size and of diversity through markets coming together. Questions that then arise are whether the 
growth of the model is followed by integration, and whether the only change is the size. Porter [8] emphasize that the definition of boundaries for the industry is dependent on the five forces and how and where they interact. When the opportunities for a company have increased and allow them to sell products and services worldwide, the definition of the industry boundaries should possibly also be extended to include this geographical expansion. As we shall see from the other effects of globalization, the answer is more complicated than a simple yes.

\subsection{Location Effects}

Porter's value chain is a visualization of the activities in a company. A company's value chain is often shown as a sequence of value chains with the down-stream supplier's value chain preceding it, and the upstream buyer's value chain following it, as shown in Figure 5. Shown this way it is a simplification of a more complex reality with a company having multiple products and services, each having multiple suppliers and customers at different levels. It does however provide a useful model for analysis.

Supplier

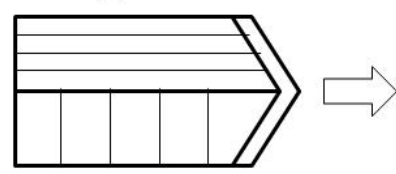

Company

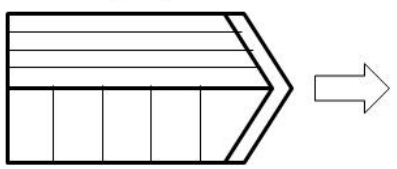

Buyer

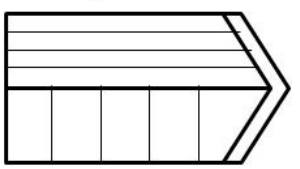

Fig. 5. The company value chain in a sequence of value chains

In order to look into the effects of fragmentation of value chains, offshoring, outsourcing and complex supply chains, it is useful to put this sequence of value chains that is representative of a company's situation into the model of the five forces of competition representing the industry's competition. This is visualized in Fig. 6 and shows one company's situation in the competition and its relationships with other players.

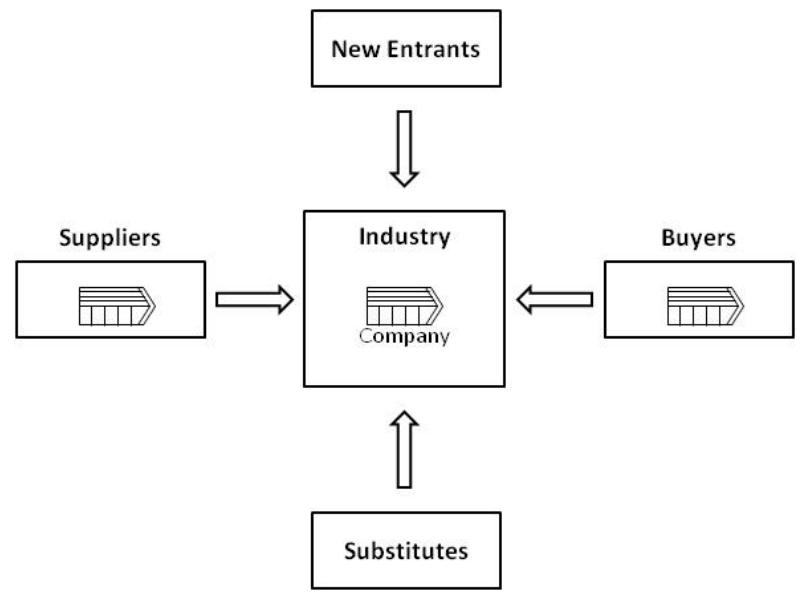

Fig. 6. A sequence of value chains represented in the model for industry competition 
Fragmentation of value chains, or vertical disintegration, leads to more specialization on individual tasks. For a traditional manufacturing company that has been limited in its geographical reach and has the production process located within that geographical reach, the fragmentation of the value chain can be seen as selection of which activities to keep within that area and within company boundaries. Figure 7 shows how the activities of a company's value chain through outsourcing can be spread out to be performed by several other companies.

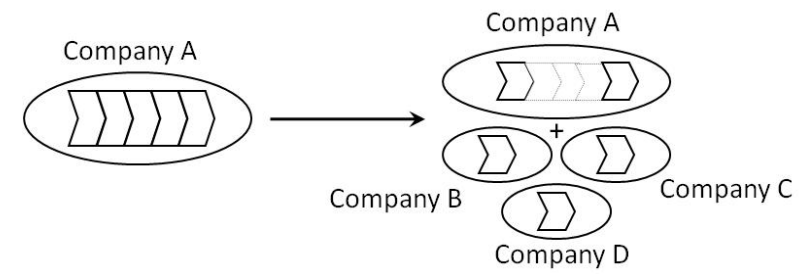

Fig. 7. Fragmentation of a simplified value chain

As the opportunities for offshoring and outsourcing have opened up through the ongoing process of globalization, the individual companies have to face these choices. The questions take the following form: for which activities is the company best able to add a higher value than competitors, and what kind of control should it have over the different activities? Mudambi and Venzin [9] state that:

"Offshoring and outsourcing are best analyzed as aspects of the global disaggregation of the value chain and as attempts by firms to combine the comparative advantages of geographic locations with their own resources and competencies to maximize their competitive advantage. The interplay of comparative and competitive advantages determines the optimal location of value chain components (offshoring decisions) as well as the boundaries of the firm and the control strategy (outsourcing decisions)."

A company can choose to keep the R\&D activities and to offshore the different production activities and assembly to locations with lower wage costs, but keep the branding and sales and marketing functions. Putting this fragmented value chain into a static picture of the model of the five forces, it might look like Figure 8. Here different geographical locations and parties of the different forces have come together in one combined market, but with regional differences of the forces. The R\&D function (1) is kept in the original location. The first part of production (2) is offshored to a second location and outsourced to a supplier that represented a potential threat. He is then included in the value chain and in the industry competition somehow, but the idea here is to look at the static picture before implementation. The second part of production (3) is outsourced to a company at a different location; again, that will be a new player in the industry and thus represents a potential new entry in the model. Assembly of the parts into a final product (4) is also carried out at a different location, but is set up as a facility owned by the company, hence being offshored but not outsourced. Another option that would be represented in the same way in the model would be to outsource assembly to a competitor or to establish a joint venture at that offshored location. The branding and marketing (5) is shown as being kept at the company's original location. 


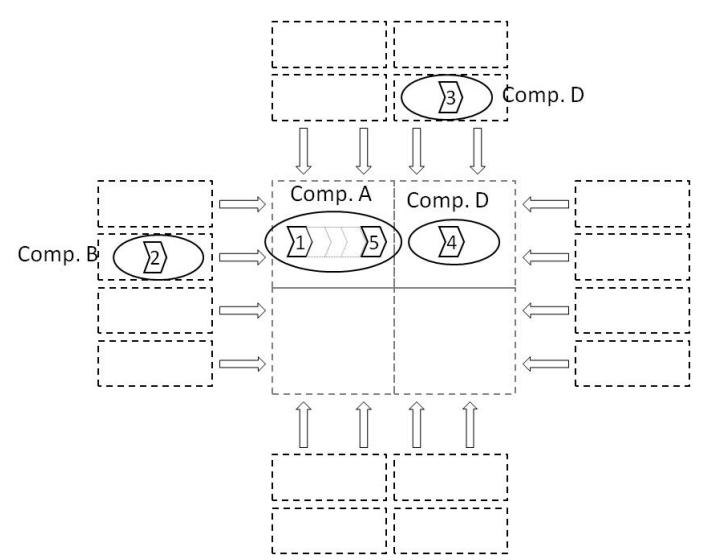

Fig. 8. Example of fragmentation and spread out of a value chain

The expanded model of the five forces can thus illustrate some of the new dynamics from these factors. In a competitive situation where offshoring and outsourcing have become viable options that reduce costs, a company may not gain competitiveness from these options if the competitors do the same, but may lose competitiveness and market position from the lack of exploiting these options. Mudambi and Venzin [9] assert that "the distribution of value creation among individual value chain activities is not static. Value creation 'travels' in terms of location and control'. This implies that the dynamics of the model will also change. Potential threats to competition become part of the industry whilst other threats vanish. The changes speed up, and the categorization of the different forces blurs as players from these categories enter or leave the competition and the interdependencies between parties increase.

\subsection{Pressure Effects}

The increased competitive pressure adds another dimension to the model. There is not only a sequential relationship between the drivers, the factors of size, the factors of location and the factors of pressure. The increased pressure on costs and prices adds to the drive for further offshoring and splitting-up activities between existing competitors and outsourcing to new ones that perform an even more specialized part of the value chain. The boundaries of the industry can then be hard to define. It may have expanded geographically, but should it still include the whole value chain as it was prior to globalization, or should the performance of the specialized tasks of the disintegrated value chain be defined as separate industries. The specialized tasks can be both an industry in itself before the interfaces between tasks change again, and they can be part of a higher-level industry. In a globalized world, the geographical boundaries can be easier to define than the industry itself. However, the increased diversity of the global market may add to the confusion of where the geographical boundaries should be placed. Lower barriers to start-up affect all the different forces. It adds to the ease with which a new player can enter the industry, as well as to how easy a substitute can be set up as a rival, or the suppliers and customers can enter the competitive arena. 
The sum is that the competition speeds up; all the forces are much more closely interrelated and affect each other. The model of the five forces of competition can be argued to have become more a model of a whirlpool, as shown in Figure 9. The industry competition is getting tougher and the changes are more frequent in terms of product development and changes to companies' roles in the model. Many players change from being part of one force to being part of several forces. Players of the different forces have the potential to impact each others as well as partaking in the speeding-up of the internal industry competition. When so many players have the potential to influence each other and induce changes, the natural further evolution of the model of competition is to continue to pick up speed of changes.

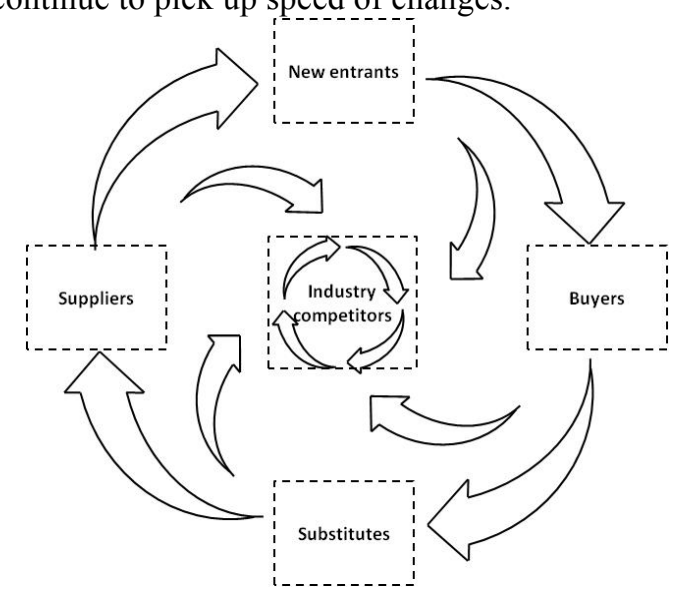

Fig. 9. The interrelations and connectedness of the forces can be represented as a whirlpool

\section{Discussion}

The general hypothesis of this paper was that the drivers and effects of economic globalization are distorting Porter's model of company competition, making it less clear and maybe less relevant. The model of the five forces of competition is affected by the drivers like lower trade barriers, lower transportation and communication costs, and technology development by the enabling of the different parties to enter the industry competition. Differences between the parties of the different forces in terms of information and technical capabilities are broken down and the effects grouped together as size expands the model in terms of bringing together previously geographically separated markets into one big global market. This, of course, is a simplification, and not a step change but something that happens gradually through the process of globalization. The gradual inclusion of India and China in the world economy can be seen this way. It is still not a complete all-encompassing free market place where everybody participates at the same level. But with the gradual inclusion of these countries, and by the evolvement of a middle class and competitive companies therein, we can see how the model of competition is gradually expanded. All the forces are affected in numbers of potential participants, and it is a gradual and continuous expansion. The effects grouped as location related, namely fragmentation of value chains, 
offshoring, outsourcing and complex supply chains, add another dynamic to the model by the dispersion of value-adding activities in the value chain to different locations inside or outside the boundaries of the company. This dispersion happens toward parties that could previously have been part of any or none of the forces of competition. The fact that the new dispersed value chain does not remain static but continues to change, and that competitors can set it up in different ways, adds to the complexity and the problem of defining the boundaries and relevant competition for an industry model. With the added effects categorized as pressure- namely cost and price pressure, higher rate of change, more diverse markets and lower start-up barriers - are included with its feedback loop to the location effects, the image of the competition model starts to resemble a whirlpool. The impact of the different drivers and effects on the competition model is shown in Figure 10.

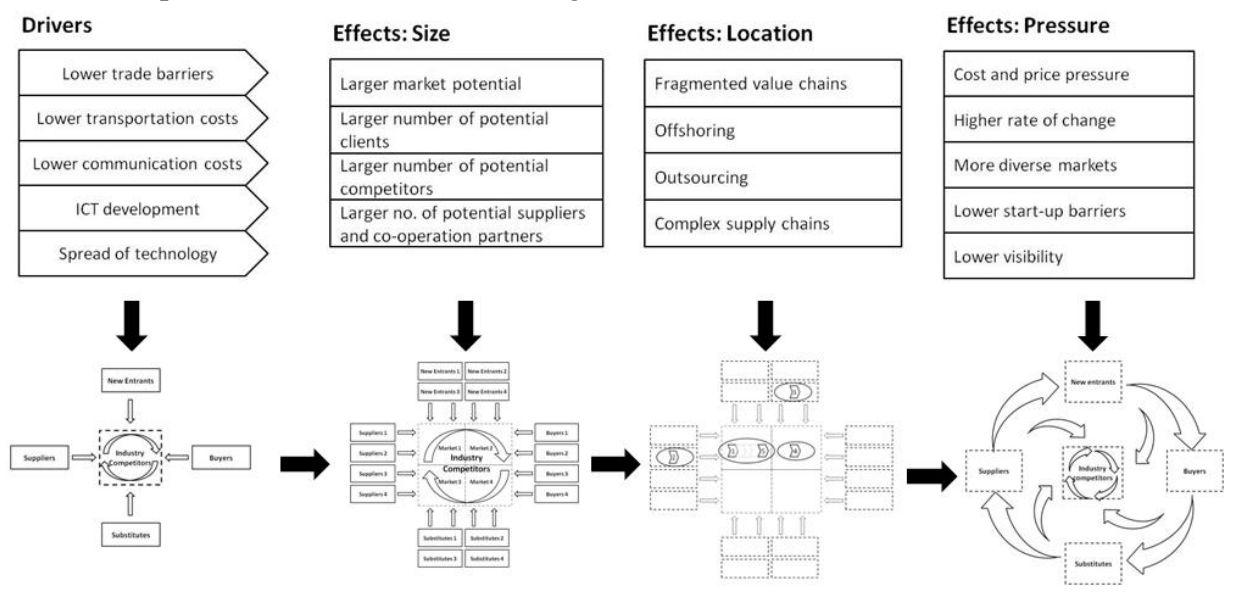

Fig. 10. The drivers and effects of globalization and how they affect the competitive situation

The whirlpool image can be used to symbolize the new interdependencies between the forces of the model and how they all have the potential to affect each other. It can be argued that the drivers and effects from globalization affect several aspects of the model at the same time, creating a different dynamic where the model might be obsolete or at least the boundaries might fade. On the other hand, it can be argued that the model enables evaluations like the one done here and therefore has become more important in a rapidly changing competitive environment as a model for understanding and analyzing our surroundings.

The model of competition and the model of the company as a value chain help explain the changes happening to companies. Disintegrating value chains, offshoring and outsourcing, and the tendency to set out production to others and focus on R\&D and the branding and marketing part of the value chain change both what the company is, its focus of operations, and the management requirements. What the company is in terms of its assets, boundaries, competence requirements and relations changes. Innovations and intellectual property rights (IPR) have become increasingly more important. The nature of the company's assets changes from physically based, to knowledge-based intellectual properties [10]. The boundaries change as the level of outsourcing and offshoring changes over time. The competence requirements change 
when the focus changes from production to innovation and IPR and the handling of a complex supply chain network. Relations to co-operation partners, suppliers in your network and competitors change over time and become more important. The company operations, or the main activities in a company, change to innovation and IPR management and to supply-chain management as the new core. The company's management requirement thus also changes to incorporate innovation and IPR focus and strategy, value chain re-engineering and network management. Put another way, globalization can totally redefine what a company is and its core.

With a larger market potential and tougher competition, the market potentials and the cost reduction potential must both be explored to keep up with industry competition. Then it is not about Porter's competitive advantages versus Ricardo's comparative advantages. On the contrary, as argued by Mudambi and Venzin [9], these should be considered together. For the individual activities of a company's value chain, both the comparative advantages of locations, and thereby possible offshoring, should be considered in combination with the company's competitive advantages for the decision to outsource or not. Since the resulting choices do not reflect a new static situation, but an interim stage on a continuous journey, it is important to include in such a consideration how today's choices will affect and limit tomorrow's choices. Another important factor is the company's ability to handle multi-location and multi-national networks of its value chain, whether or not parts of it are outsourced and thereby inside or outside the boundary of the company. Handling these types of questions and of this magnitude and importance for the company is a relatively new management responsibility and requirement that has evolved over the last few decades, during which the pace of globalization has accelerated. As globalization continues to gain speed and strength, it is likely that more and more companies and managers will be affected.

\section{Conclusions}

It is observed that some of the characteristics of the competition model have changed. Firstly, the boundaries of the forces of the model are fading. The drivers of competition affect all the five forces and make their opportunities more equal, and the entry barriers to the industry's internal competition are lowered. Secondly, the model has become less static, with the value-adding activities of the value chain of companies shifting around both locations and within and outside the company's boundaries. Further, the forces and the market are more diverse than before. Even though products and services can have a global potential, the market segment can have very different preferences, and the players can have different business practices. Defining the boundaries of the industry has, in itself, become more difficult.

The competitive situation a company operates in has become more uncertain with lower visibility and higher uncertainty: a new dynamic with a higher speed of change and potential new interaction and relationship between the players. Fragmentation of value chains and complex supply chains make the picture more complex and the individual company's position more uncertain, both on relative strength in the overall competition and on the future direction. Globalization opens up opportunities of offshoring and outsourcing, and through these options being available to industry competitors, forces decisions on these areas of company value activities, their locations 
and company boundaries. In utilizing these options, companies tend to shift the focus to innovation and intellectual property rights, and to branding. This shift has the potential to redefine what a company is and its core from products or production to innovation and IPR.

As areas for further study, the authors point to the changes in assets and the resulting necessary changes to the area of asset management, and to the changes in management requirements in general.

\section{References}

1. Porter, M. E.: How Competitive Forces Shape Strategy. Harvard Business Review, March/April, pp. 137-145 (1979)

2. Bang, K.E. and Markeset, T.: Identifying the drivers of economic globalization and the effects on companies' competitive situation, In: The Proceedings of the International Conference on Advances in Production Management Systems, Stavanger, Norway, September 26-28 $8^{\text {th }}(2011)$.

3. Porter, M. E.: Competitive Advantage: Creating and Sustaining Superior Performance. New York: The Free Press (1985)

4. Friedman, T.L.: The World is Flat: A Brief History of the Twenty-First Century. New York: Farrar, Straus and Giroux (2005)

5. Porter, M. E.: Strategy and the Internet. Harvard Business Review, March, pp. 63-78 (2001)

6. Porter, M. E.: The Competitive Advantage of Nations. New York: The Free Press (1990)

7. Ricardo, D.: On the Principles of Political Economy and Taxation. 3rd ed. [e-book] London: John Murray. Available through: Library of Economics and Liberty $<\mathrm{http}: / /$ www.econlib.org/index.html $>$ [Accessed February $3^{\text {rd }}$ 2011] (1821)

8. Porter, M. E.: The Five Competitive Forces that Shape Strategy. Harvard Business Review, January, pp. 79-93 (2008)

9. Mudambi, R. and Venzin, M.: The Strategic Nexus of Offshoring and Outsourcing Decisions. Journal of Management Studies, 47 (8), December, pp. 1510-1533 (2010)

10. Fatehi, K., Veliyath, R. and Derakhshan, F.: Emergent Realities of Global Competition: The Changing Demands on Managers and Governments. International Journal of Commerce and Management, 18 (1), pp. 77-92 (2008) 